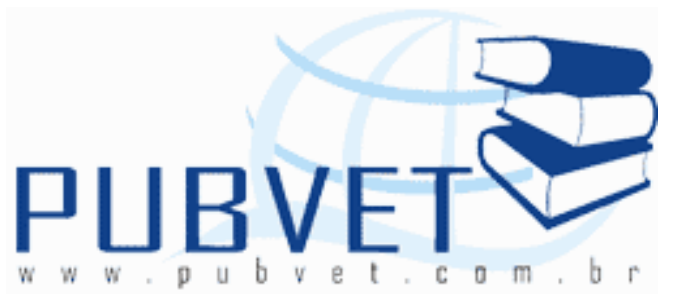

PUBVET, Publicações em Medicina Veterinária e Zootecnia.

\title{
Avaliação da influência do clima via características termorreguladoras de vacas leiteiras nos períodos seco e chuvoso do ano em Bom Jesus Piauí
}

Cícero Pereira Barros Junior ${ }^{1}$; Carlos Syllas Monteiro Luz ${ }^{1}$; Wéverton José Lima Fonseca ${ }^{2}$; Eudes Sousa Araújo²; Gioto Ghiarone Terto e Sousa ${ }^{3}$; Severino Cavalcante de Sousa Júnior ${ }^{4}$

${ }^{1}$ Bolsista de Iniciação Cientifica (ICV), curso de Bacharelado em Zootecnia, Universidade Federal do Piauí, Bom Jesus, Brasil.

${ }^{2}$ Graduando do curso de Bacharelado em Zootecnia, Universidade Federal do Piauí, Bom Jesus, Brasil.

${ }^{3}$ Pós-Graduando em Ciência Animal, Universidade Federal do Piauí, Teresina, Brasil.

${ }^{4}$ Docente do curso de Bacharelado em zootecnia, Universidade Federal do Piauí, Bom Jesus, Brasil.

\section{Resumo}

Foram avaliadas as características termorreguladoras de vacas Mestiças Holandês x Gir em lactação nos períodos seco e chuvoso durante os turnos da manhã e tarde, e correlacionar com variáveis meteorológicas registradas ao longo do ano na fazenda experimental do Colégio Agrícola pertencente à Universidade Federal do Piauí - CPCE. Foi coletado dados como a frequência respiratória (FR), temperatura retal (TR) e taxa de sudação (TS). A análise 
BARROS JUNIOR, C.P. et al. Avaliação da influência do clima via características termorreguladoras de vacas leiteiras nos períodos seco e chuvoso do ano em Bom Jesus Piauí. PUBVET, Londrina, V. 6, N. 35, Ed. 222, Art. 1475, 2012.

física do ambiente térmico da instalação foi adquirida na estação meteorológica do Campus Profa. Cinobelina Elvas, localizada na cidade de Bom Jesus-PI, que registrou a temperatura do ar (TA) e a umidade do ar (UR). O índice de temperatura de globo e umidade (ITGU) foi obtido através de aferição direta do globo negro no local das coletas. Os animais foram avaliados a cada dois dias, em dois turnos, às $9 \mathrm{~h}$ e às $15 \mathrm{~h}$, durante o período seco (agosto á novembro) e chuvoso (janeiro á maio). Os animais apresentaram maiores (TS) no período seco no turno da manha $\left(110,28^{\mathrm{a}}\right)$, já no período chuvoso o maior índice foi no turno da tarde $\left(104,12^{\mathrm{a}}\right)$. As médias de (FR) mostraram maiores valores no período chuvoso no turno da tarde $\left(38.89^{\mathrm{a}}\right)$. Os maiores valores para ITGU foram observados no período seco no turno da tarde $\left(93.30^{\mathrm{a}}\right)$, possivelmente devido à (TA) terem apresentados valores diferentes em ambos os períodos e turnos. O conhecimento das diferenças das variáveis meteorológicas e fisiológicas entre os períodos e turnos nos mostra a capacidade dos animais de manter a sua homeotermia mesmo com o estresse calórico que o ambiente lhes oferece.

Palavras-chave: Bovinos leiteiros; Frequência respiratória; Homeotérmia; Temperatura retal.

\title{
Evaluation of the influence of climate features via thermoregulatory of dairy cows in dry and rainy periods of the year in Bom Jesus-Piauí
}

\begin{abstract}
We evaluated the thermoregulatory characteristics of lactating crossbred Holstein $x$ Gir cows in the dry and wet periods during the morning and afternoon, and correlated with meteorological variables recorded throughout the year at the experimental farm belonging to the Agricultural College of the Federal University of Piauí - CPCE. Form collected data such as respiratory rate $(R R)$, rectal temperature (RT) and sweating rate (SR). The physical analysis of the thermal environment of the facility was acquired by the weather station Campus Prof. Cinobelina Elvas, in the city of Bom Jesus, PI, which recorded the
\end{abstract}


BARROS JUNIOR, C.P. et al. Avaliação da influência do clima via características termorreguladoras de vacas leiteiras nos períodos seco e chuvoso do ano em Bom Jesus Piauí.

PUBVET, Londrina, V. 6, N. 35, Ed. 222, Art. 1475, 2012.

air temperature $(T A)$ and humidity $(\mathrm{RH})$. The rate of globe temperature and humidity (BGT) was obtained by direct measurement of the black spot of the globe collecting the animals were measured every two days, in two rounds at 9 am and $15 \mathrm{pm}$, during the dry period (August to November) and rainy season (January to May). Animals had higher (TS) during the dry period in the morning $\left(110.28^{\mathrm{a}}\right)$, since the rainy season was the highest in the afternoon $\left(104.12^{\mathrm{a}}\right)$. As the mean (FR) showed higher values during the rainy season in the afternoon $\left(38.89^{\mathrm{a}}\right)$. The highest values for BGT were observed during the dry period in the afternoon $\left(93.30^{\mathrm{a}}\right.$ ), possibly due to (TA) have presented different values in both periods and shifts. Knowledge of differences in meteorological and physiological variables between the periods and shift shows the ability of animals to maintain their homeothermy even with the heat stress that the environment offers them.

Keywords: dairy cattle; rectal temperature; respiratory rate; thermoregulation.

\section{Introdução}

A agropecuária Brasileira é o setor mais competitivo de economia nacional, já que a produção agrícola exportada e o setor agropecuário é o único setor da atividade econômica que tem superávit na relação de comércio internacional. De acordo com MULLER (1989) as raças bovinas europeias diminuem o potencial de crescimento quando submetidas a temperaturas constantes acima de $24^{\circ} \mathrm{C}$ e os efeitos se agravam para temperaturas de 29 $32^{\circ} \mathrm{C}$, pois praticamente cessa o aumento de pés; em temperaturas acima de $41^{\circ} \mathrm{C}$ sobrevivem à prostração, se especialmente a umidade relativa do ar é alta. O animal dentro de um ambiente térmico considerado adequado produzirá de acordo com o seu potencial genético, em que os limites térmicos do ambiente estabelecidos como confortantes ou estressantes, podem sofrer variações em função da região e dos tipos/raças de animais utilizados na propriedade (PERISSINOTTO et al., 2009). 
A adaptabilidade, ou capacidade de se adaptar, pode ser avaliada pela habilidade do animal em se ajustar às condições ambientais médias, assim como aos extremos climáticos exigindo um melhor conhecimento das espécies e raças que apresentem potencial genético com maior capacidade de adaptabilidade, sendo capazes de sobreviver, produzir e reproduzir-se em condições adversas de clima (SOUZA et al., 2007).

Os bovinos são animais homeotérmicos, ou seja, tende a manter a temperatura corporal constante através do fluxo de calor determinado por processos que dependem da temperatura (condução, convecção e radiação) e da umidade (evaporação, via transpiração e respiração) ambiente. Quando submetidas a temperaturas ambientais elevadas, mecanismos controladores ligados, diretamente, às respostas fisiológicas são acionados, na tentativa de dissipar calor e manter a homeostase térmica, sendo comum um incremento da temperatura retal, que se torna mais intenso com o grau de desvio da temperatura de conforto térmico (MARTINS et al., 2008).

A partir de parâmetros fisiológicos como, a temperatura retal e frequência respiratória, para muitos pesquisadores são considerados as melhores referências fisiológicas para estimar a tolerância dos animais ao calor. Os animais que apresentam menor aumento na temperatura retal e menor frequência respiratória são considerados mais tolerantes ao calor (SOUZA et al., 2007).

O objetivo deste trabalho foi avaliar as características termorreguladoras de vacas Mestiças (Holandês x Gir), em dois turnos, nos períodos seco e chuvoso, e correlacioná-las com as variáveis meteorológicas obtidas em Bom Jesus região Sul do Estado do Piauí.

\section{Material e métodos}

O trabalho foi desenvolvido na fazenda experimental do Colégio Agrícola, pertencente à Universidade Federal do Piauí, no município de Bom Jesus, região Sul do estado do Piauí. Foram utilizados dados de dez vacas Mestiças (Holandês x Gir), em lactação. Porém, verificou-se a ocorrência de 
BARROS JUNIOR, C.P. et al. Avaliação da influência do clima via características termorreguladoras de vacas leiteiras nos períodos seco e chuvoso do ano em Bom Jesus Piauí.

PUBVET, Londrina, V. 6, N. 35, Ed. 222, Art. 1475, 2012.

um período chuvoso, geralmente de janeiro a maio, além de um período de estiagem de agosto a novembro, de acordo com os dados que foram abordados neste respectivo trabalho pode se observar uma variabilidade de dados tanto nos turnos como nos período que foram pesquisados, mesmo com altos valores nos parâmetros fisiológicos, pode se concretizar que esses animais se encontram adaptados ao ambiente.

Foram escolhidas aleatoriamente dez vacas mestiças (Holandês x Gir), com mais de dois anos de idade, com peso médio de 400 a $500 \mathrm{~kg}$, aptidão para produção de carne e de leite, e pelagem variada, como vermelhas, castanhas, pretas e brancas. As características do pelame dos bovinos estão associadas á sua capacidade de tolerância as variações climáticas do ambiente, sendo importantes na adaptação dos animais ao seu ambiente.

Os dados foram coletados semanalmente durante os meses de agosto a novembro, correspondentes ao período seco e de janeiro a maio, correspondentes ao período chuvoso. Foram realizadas duas coletas diárias: pela manhã, das 9:00 h às 10:00 h e pela tarde, das 15:00 h às 16:00 h. De imediato foi registrada nos animais a frequência respiratória FR em movimentos respiratório por minuto, através da observação direta dos movimentos do flancos esquerdo; em seguida foi registrara a temperatura retal TR por meio de um termômetro clínico introduzido diretamente no reto dos animais durante dois minutos. Posteriormente foi estimada a taxa da sudação TS, pelo método calorimétrico de SCHLEGER e TURNER (1965), adaptado por SILVA (2000).

No ambiente foram registradas as temperaturas do termômetro de bulbo seco (temperatura do ar) e do termômetro de bulbo úmido, no início e fim de cada coleta, com as quais foi estimada a umidade do ar; Nesses mesmos horários foram registradas as temperaturas do termômetro de globo negro, com as quais se calcularam o Índice de Temperatura de Globo e Umidade (ITGU), segundo metodologia usada por MORAIS (2008), através das equações a seguir: 
BARROS JUNIOR, C.P. et al. Avaliação da influência do clima via características termorreguladoras de vacas leiteiras nos períodos seco e chuvoso do ano em Bom Jesus Piauí.

PUBVET, Londrina, V. 6, N. 35, Ed. 222, Art. 1475, 2012.

Pressão Parcial de Vapor (Pp\{Ta\})

$\operatorname{Pp}\{\mathrm{Ta}\}=\operatorname{Ps}\{\mathrm{Tu}\}-\mathrm{Y}(\mathrm{Ta}-\mathrm{Tu})$

\section{Sendo:}

$\operatorname{Ps}\{\mathrm{Tu}\}=$ pressão de saturação à temperatura $\mathrm{Tu}(\mathrm{kPa})$

$\mathrm{Y}=$ constante psicrométrica, $\left(\mathrm{kPa} /{ }^{\circ} \mathrm{C}\right)$

$\mathrm{Ta}=$ temperatura do ar ou de bulbo seco $\left({ }^{\circ} \mathrm{C}\right)$

$\mathrm{Tu}=$ temperatura do bulbo úmido $\left({ }^{\circ} \mathrm{C}\right)$

Índice de Temperatura de Globo e Umidade (ITGU)

ITGU $=\mathrm{Tg}+0,36 \mathrm{Tpo}+41,5$

\section{Sendo:}

$\mathrm{Tg}$ = temperatura do termômetro de globo $\left({ }^{\circ} \mathrm{C}\right)$

Tpo $=$ temperatura do ponto de orvalho $\left({ }^{\circ} \mathrm{C}\right) 41,5=$ constante

Os dados foram submetidos a teste de homogeneidades de variância residual, análises de variância e de correlação entre as variáveis analisadas. Para comparar os resultados foi realizado o teste de Tukey $(P<0,05)$, utilizando-se o pacote estatístico SAS (2003), versão 9.3. A análise estatística será realizada pelo método dos quadrados mínimos, conforme HARVEY (1960), tendo como base o seguinte modelo:

$$
Y_{i j k l m}=\mu+G_{i}+A_{j i}+H_{k}+E_{l}+I T G U_{i j k l}+F R_{i j k l}+T R_{i j k l}+e_{i j k l m}
$$

\section{Sendo:}

$\mathrm{Y}_{\mathrm{ijklm}}=\mathrm{m}$-ésima média

$\mu=$ é a média geral;

$\mathrm{GG}_{\mathrm{i}}=$ efeito fixo da i-ésima raça,

$A_{j i}=$ efeito aleatório do j-ésimo animal pertencente a i-ésima raça;

$\mathrm{H}_{\mathrm{k}}=$ é o efeito fixo do k-ésimo horário de coleta,

$E_{l}=$ é o efeito fixo do l-ésima época de coleta, 
BARROS JUNIOR, C.P. et al. Avaliação da influência do clima via características termorreguladoras de vacas leiteiras nos períodos seco e chuvoso do ano em Bom Jesus Piauí.

PUBVET, Londrina, V. 6, N. 35, Ed. 222, Art. 1475, 2012.

$\mathrm{ITGU}_{\mathrm{ijkl}}=$ Índice de Temperatura de Globo e Umidade da I-ésima coleta, jésimo animal pertencente ao i-ésima raça

$\mathrm{FR}_{\mathrm{ijkl}}=$ freqüência respiratória da l-ésima coleta, j-ésimo animal pertencente ao i-ésima raça

$\mathrm{TR}_{\mathrm{ijkl}}=$ Taxa de sudação da I-ésima coleta, j-ésimo animal pertencente ao iésima raça

$\mathrm{e}_{\mathrm{ijklm}}=$ é o resíduo, incluindo o erro aleatório.

As funções fisiológicas: (Frequência respiratória - FR) foi aferida por meio da observação dos movimentos dos flancos em um minuto, a (Taxa de sudação - TS) foi aferida em minutos por meio de uma tricotomia na região do costado dos animais onde foram fixados três discos de papel filtro cada um com $25 \mathrm{~mm}$ de raio, que foram dissecados com cloreto de cobalto a $10 \%$. A (Temperatura Retal - TR) foi aferida por meio de um termômetro clínico em $\left(\mathrm{T}^{0} \mathrm{C}\right)$ que foi introduzido no reto dos animais com um tempo de dois minutos.

Os bovinos são animais altamente adaptados às condições do semiárido, e que por meio de técnicas de exploração racional, tem demonstrado resultados positivos. A eficácia de sobrevivência desses grandes ruminantes foi avaliada durante a execução deste trabalho, com isso esses animais são capazes de fazer a termorregulação que e o processo de controle de temperatura em um sistema qualquer constituindo em uma adaptação evolutiva que os permite viver em ambientes de temperaturas variadas.

\section{Resultados e discussão}

Os resultados referentes às interpretações das análises feitas com dados aferidos no período seco (agosto a novembro de 2010) e chuvoso (janeiro a maio de 2011), nos turnos da manhã e tarde, que apresenta o registro das variáveis meteorológicas durante os períodos e o turno que foram realizados o experimento, onde pode se perceber uma amplitude térmica de $4.33 \mathrm{C}^{0} \mathrm{com}$ superioridade para o período seco do ano em que foi registrado, provavelmente devido à maior incidência de raios solares. Observou-se que em 
BARROS JUNIOR, C.P. et al. Avaliação da influência do clima via características termorreguladoras de vacas leiteiras nos períodos seco e chuvoso do ano em Bom Jesus Piauí.

PUBVET, Londrina, V. 6, N. 35, Ed. 222, Art. 1475, 2012.

relação aos períodos e os turnos foram verificadas diferenças significativas, para todas as características meteorológicas nos períodos estudados. Mostrando assim, que os animais estão submetidos a grandes variações térmicas e de unidade durante o dia, devido à variação significativa encontrada entre os turnos da manhã e da tarde, e todo o ano, pois foi observada também diferença significativa entre as estações do ano (tabela 1).

SOUSA JÚNIOR (2008) constatou na época seca na Paraíba, temperatura ambiente de $38,2^{\circ} \mathrm{C}$ e temperatura de globo negro de $38,9^{\circ} \mathrm{C}$. Esse valor é bem similar ao que (ROCHA et al., 2009) constataram no Piauí, 36,5 e $38,0^{\circ} \mathrm{C}$, respectivamente, também foi confirmado nessa pesquisa que os animais que estão expostos nessa região estão sujeito a uma alta variação térmica com alto poder de estresse por calor na maior parte do ano.

A alta temperatura ambiente que ocorre comumente no segundo semestre do ano, tem sido considerada estressante para os bovinos, mas pode se constar que nas condições ambientais que foi observada no decorrer da pesquisa, a homeotermia por vasodilatação periférica tenderia a apresentar eficiência relativamente baixa, pois entre a temperatura corporal e a ambiental foi pequeno, limitando assim o fluxo de calor por processo não evaporativo (condução, convecção e radiação), conforme afirma SILVA (2000) e também SOUSA JÚNIOR (2008). Ser necessário para esse processo se mostrar eficiente. Porém, não deve ser desconsiderado o fato da umidade relativa se apresentar sempre baixa nessa época do ano, com isso facilitaria a perda de calor pela sudorese.

Tabela 1. Médias das variáveis meteorológicas e índices de conforto térmico de animais mestiços (Holandês x Gir) em lactação durante os turnos da (manhã e tarde) nos períodos (seco e chuvoso), em Bom Jesus-PI.

\begin{tabular}{lcccc}
\hline Características* & \multicolumn{2}{c}{ Período Seco } & \multicolumn{2}{c}{ Período Chuvoso } \\
& Manhã & Tarde & Manhã & Tarde \\
\hline TA $\left(\mathrm{C}^{0}\right)$ & $23.43^{\mathrm{b}}$ & $26.28^{\mathrm{a}}$ & $21.95^{\mathrm{b}}$ & $28.38^{\mathrm{a}}$ \\
UA $(\mathrm{KPa})$ & $55.25^{\mathrm{a}}$ & $50.25^{\mathrm{b}}$ & $93.80^{\mathrm{a}}$ & $67.30^{\mathrm{b}}$ \\
ITGU $\left(\mathrm{C}^{\mathrm{D}}\right)$ & $83.68^{\mathrm{b}}$ & $93.30^{\mathrm{a}}$ & $83.60^{\mathrm{b}}$ & $85.41^{\mathrm{a}}$ \\
\hline
\end{tabular}

Médias seguidas de mesma letra não diferem pelo Teste de Tukey ao nível de 5 $\%$ de significância. Temperatura do ar (TA); Umidade do $\mathrm{Ar}$ (UA); Índice de Temperatura Globo e Umidade (ITGU). 
BARROS JUNIOR, C.P. et al. Avaliação da influência do clima via características termorreguladoras de vacas leiteiras nos períodos seco e chuvoso do ano em Bom Jesus Piauí.

PUBVET, Londrina, V. 6, N. 35, Ed. 222, Art. 1475, 2012.

Os valores para o ITGU foram verificados diferenças significativas $(\mathrm{P}<0.05)$ tanto para turno como para período, com maiores valores no período seco no turno da tarde $\left(93.30 C^{0}\right)$ possivelmente devido à temperatura do ar (TA) ter apresentando índices significativos ( $P<0.05)$, apresentando valores variados tanto nos turnos quanto nos períodos, aumentando certos parâmetros fisiológicos, o que pode aumentar o estresse dos animais, devido às dificuldades das trocas térmicas por evaporação. Segundo Morais (2008) o índice de temperatura de globo e umidade ITGU praticamente variou e apresentou valores altos, caracterizando ambiente estressante no período seco no turno da tarde (tabela 1 ).

Em relação à umidade do ar UA os valores dos turnos e períodos variaram positivamente, podendo se concretizar que os períodos e os turnos apresentaram aporte térmico diferenciados com maior índice numérico no periodo chuvoso no turno da manha $(93.80 \mathrm{KPa})$ possivelmente devido a função da maior concentração de vapor d'água na atmosfera, consequentemente o ITGU apresentou menor valor nesse respectivo horário. Segundo PIRES (2006). Os animais podem apresentar sinais de estresse, uma vez que, tal temperatura ambiente encontra-se na faixa entre $26^{\circ} \mathrm{C}$ e $32^{\circ} \mathrm{C}$ e a umidade relativa do ar entre 50 a $90 \%$.

A temperatura do ar tem sido considerada o fator climático com influência marcante sobre o ambiente físico do animal, esse, quando submetido a estresse calórico recorre a mecanismos termorregulatórios para manter a homeotermia. A temperatura retal TR tem sido usada como indicador do equilíbrio térmico na avaliação do impacto do estresse calórico sobre o animal (MADER et al., 2005). 
BARROS JUNIOR, C.P. et al. Avaliação da influência do clima via características termorreguladoras de vacas leiteiras nos períodos seco e chuvoso do ano em Bom Jesus Piauí.

PUBVET, Londrina, V. 6, N. 35, Ed. 222, Art. 1475, 2012.

Tabela 2. Média de temperatura retal, frequência respiratória e taxa de sudação durante os turnos da (manhã e tarde) e nos períodos (seco e chuvoso) de vacas (Mestiças Holandês x Gir) em lactação, em Bom Jesus-PI.

\begin{tabular}{lcccc}
\hline Características* & \multicolumn{2}{c}{ Período Seco } & \multicolumn{2}{c}{ Período Chuvoso } \\
& Manhã & Tarde & Manhã & Tarde \\
\hline FR $($ mov./mim. $)$ & $49.57^{\mathrm{a}}$ & $53.75^{\mathrm{a}}$ & $52.21^{\mathrm{b}}$ & $58,10^{\mathrm{a}}$ \\
TR $\left({ }^{\circ} \mathrm{C}\right)$ & $38.92^{\mathrm{a}}$ & $38.93^{\mathrm{a}}$ & $38.75^{\mathrm{a}}$ & $38,89^{\mathrm{a}}$ \\
TS $(\mathrm{g} / \mathrm{m} / \mathrm{h})$ & $110.28^{\mathrm{a}}$ & $108.57^{\mathrm{a}}$ & $86.46^{\mathrm{b}}$ & $104.12^{\mathrm{a}}$ \\
\hline
\end{tabular}

Médias seguidas de mesma letra não diferem pelo Teste de Tukey ao nível de 5 \% de significância. Frequência Respiratória (FR); Temperatura Retal (TR); Taxa de Sudação (TS).

As médias das variáveis termorreguladoras dos animais estudados na Tabela 2. Não foi verificada diferença significativa $(P>0,05)$ para nenhuma das variáveis avaliadas no período seco. Pode-se observar que a frequência respiratória (FR), temperatura retal (TR) e taxa de sudação (TS) nos turnos da manhã e tarde demonstram que esses animais sudaram mais e respiraram menos no período seco, e promovendo o inverso no periodo chuvoso, o que se pode afirmar e que esses animais utilizar seus mecanismos termo reguladores para manter a homeotermia nas diferentes épocas do ano, que e diferenciada pelas altas temperaturas. Sendo (estes os mecanismos mais utilizados nas condições estudadas). Os animais apresentaram elevação do estoque de calor corporal, ocasionando a maior necessidade de dissipação de calor e aumentando a frequência respiratória e a sudorese. (MAIA et al., 2005) verificaram que em bovinos manejados sob condições de alta temperatura e radiação, a dissipação de calor se dá principalmente por mecanismos evaporativos, sendo a evaporação cutânea responsável por aproximadamente $80 \%$ dessas perdas.

A temperatura retal TR não apresentou diferença significativa $(P>0.05)$ entre os turnos nos respectivos períodos. Esta media é frequentemente usada como índice de adaptabilidade fisiológica aos ambientes quentes, pois seu aumento mostra que os mecanismos de liberação de calor tornaram-se insuficientes para manter a homeotérmia SILVA (2000). 
Em ambientes com temperatura do ar acima do limite a via evaporativa torna-se a principal maneira de troca de calor (respiração e sudação). Segundo (LIGEIRO et al., 2006) a capacidade máxima de sudação é atingida sob temperaturas elevadas e umidade baixa, quando ocorre aumento do volume de sangue para a epiderme, que proporciona maior estímulo para produção das glândulas sudoríparas.

Quando a temperatura ambiente se eleva, aproximando-se do valor da temperatura corporal, a gradiente de temperatura torna-se pequeno e reduz a eficiência das perdas de calor pela forma sensível, acionando o mecanismo de transferência de calor por processos evaporativos (MARTELO et al., 2006). A respiração e sudação são as formas evaporativas utilizadas por esse mecanismo de transferência de calor.

Por sua vez, a frequência respiratória, que variou de 49,57 a 58,10 mov./min, contribuiu de forma efetiva para essa adaptação, visto que, segundo SOUSA JÚNIOR (2008) a variação normal em bovinos no nordeste brasileiro é de 42 a $60 \mathrm{mov} / \mathrm{min}$. durante o ano.

\section{Conclusões}

Verificou-se que, nesse estudo os parâmetros fisiológicos dos animais apresentaram menor aquecimento corporal e termolise no periodo chuvoso no turno da manha, devido à menor incidência de radiação solar, e a umidade do ar ter sido maior em relação ao período seco. Em relação aos períodos e turnos os animais apresentaram maior perda de calor por termolise evaporativa no periodo seco no turno da manhã, devido este período ter apresentado também o maior índice de temperatura de globo negro (ITGU). Tornando assim, este período o mais estressante para vacas mestiças (Holandês x Gir) em lactação, no Sul do Estado do Piauí. 


\section{Referências bibliográficas}

MULLER, P. B.; Bioclimatologia aplicada aos animais domésticos. $3^{a}$ ed., porto alegre, livraria editora sulina. 1989; 158p.

PERISSINOTTO, M.; MOURA, D. J.; CRUZ, V. F.; SOUZA, S. R. L; LIMA KAO, MENDES, A. S.; Conforto térmico de bovinos leiteiros confinados em clima subtropical e mediterrâneo pela analise de parâmetros fisiológicos utilizando a teoria dos conjuntos fuzzy. Revista ciência rural, v. 39, n. 5. 2009; p. 1492-1498.

SOUZA, B. B.; SILVA, R. M. N.; MARINHO, M. L.; Parâmetros fisiológicos e índice de tolerância ao calor de bovinos da raça Sindí no semiárido paraibano. Ciências e Agrotecnologia, v. 31, n. 3, 2007.

MARTINS, T. D. D.; COSTA, A. N.; Desempenho e comportamento de fêmeas suínas lactantes criadas em climas tropicais. Archivos de Zootecnia. Vol. 57(R), 2008; p. 83.

SOUZA, B. B.; Adaptabilidade e bem-estar em animais de produção. 2007; Disponível em: <HTTP://www.infobibos.>. Acessado em 19 de agosto de 2011.

SCHLEGER, A. V.; TURNER, H. G.; Sweating rates of cattle in the field and their reaction to diurnal and seasonal changes. Australian Journal Agricultural research, Vol. 16, 1965; p. 92-106.

SILVA, R. G.; Introdução à Bioclimatologia Animal. São Paulo: Nobel. 2000; 129p. 286p.

MORAIS, D. A. E. F. MAIA, A. S. C.; SILVA, R. G.; Variação anual de hormônios tireoide anos e características termorreguladoras de vacas leiteiras em ambiente quente. Revista Brasileira de Zootecnia. Vol. 37, n.3, 2008; p.538-545.

SAS Institute. SAS (Statistical Analysis System). User's Guide. Cary, NC: SAS Institute. Inc. 2003; 129p.

HARVEY, W. R.; Least squares analysis of data with unequal suclass numbers. Beltsville, md: ars/USDA, publ. 1960.

SOUSA JÚNIOR, S. C.; Características termorreguladoras de caprinos, ovinos e bovinos em diferentes épocas do ano em região semiárida. Revista científica de Produção Animal. Vol. 10, n.2, p.127-137, 2008.

Rocha, R. R. C. Costa, A. P. R.; Azevedo, D. M. M. R.; Nascimento. H. T. S.; Cardoso, F. S.; Muratori, M. C. S.; Adaptabilidade climática de caprinos saanen e azul no meio-norte do brasil. Arquivo Brasileiro de Medicina Veterinária e Zootecnia. Vol. 61, n. 5, 2009; p.11651172.

MORAIS, D. A. E. F.; variação anual de hormônios tireoidianos e características termorreguladoras de vacas leiteiras em ambiente quente. Revista brasileira de zootecnia. Vol. 37, n. 3, p.538-545, 2008.

PIRES, M. F. Á.; modificações ambientais para reduzir o estresse calórico em gado de leite. Comunicado Técnico 52, Juiz de Fora, MG, 2006. 
MADER, T.; SPIERS, D. E.; PARKURT, A. M.; Analyses of thermoregulatory responses of feeder cattle exposed to simulated heart waves. International Journal of Biometeorology. Lisse, Vol. 49, 2005; P.285-296.

MAIA, A. S. C.; SILVA, R. G.; Sensible and latent heat loss from the body surface of Holstein cows in tropical environment. Int. I. Biometeorology. Vol. 50, n. 1, 2005; p.17-22.

LIGEIRO, E. C.; MAIA, A. S. C.; SILVA, R. G.; perda de calor por evaporação cutânea associada às características morfológicas do pelame de cabras leiteiras criadas em ambiente tropical. Revista Brasileira de Zootecnia, Viçosa, Vol.35, n.2, 2006; p.544-549.

MARTELO, L. S.; interação animal-ambiente: efeito do ambiente climático sobre as repostas fisiológicas e produtivas de vacas holandesas em free-stall. Luciane Silva Martello - tese (doutorado), orientador: Prof. Dr. Holmer Savastano Junior - Faculdade de Zootecnia Engenharia de Alimentos - USP-Pirassununga, 111 f., 2006. 